\title{
Feasibility and safety of intraoperative BOLD functional MRI cerebrovascular reactivity to evaluate extracranial-to-intracranial bypass efficacy
}

\author{
*Giovanni Muscas, MD, ${ }^{1-3}$ Christiaan Hendrik Bas van Niftrik, MD, ${ }^{1,3}$ Jorn Fierstra, MD, PhD, 1,3 \\ Marco Piccirelli, PhD, ${ }^{3,4}$ Martina Sebök, MD, ${ }^{1,3}$ Jan-Karl Burkhardt, MD, ${ }^{1,5}$ Antonios Valavanis, MD, ${ }^{3}$ \\ Athina Pangalu, MD, ${ }^{3,4}$ Luca Regli, MD, ${ }^{1,3}$ and Oliver Bozinov, MD ${ }^{1,3}$

\begin{abstract}
1Department of Neurosurgery, University Hospital Zurich, University of Zurich, Switzerland; '2Department of Neurosurgery, Careggi Hospital, University of Florence, Italy; ${ }^{3}$ Clinical Neuroscience Center, University Hospital Zurich; and ${ }^{4}$ Department of Neuroradiology, University Hospital Zurich, University of Zurich, Switzerland; and ${ }^{5}$ Department of Neurosurgery, Baylor College of Medicine Medical Center, Houston, Texas
\end{abstract}

\begin{abstract}
Blood oxygenation level-dependent functional MRI cerebrovascular reactivity (BOLD-CVR) is a contemporary technique to assess brain tissue hemodynamic changes after extracranial- intracranial (EC-IC) bypass flow augmentation surgery. The authors conducted a preliminary study to investigate the feasibility and safety of intraoperative 3-T MRI BOLD-CVR after EC-IC bypass flow augmentation surgery. Five consecutive patients selected for EC-IC bypass revascularization underwent an intraoperative BOLD-CVR examination to assess early hemodynamic changes after revascularization and to confirm the safety of this technique. All patients had a normal postoperative course, and none of the patients exhibited complications or radiological alterations related to prolonged anesthesia time. In addition to intraoperative flow measurements of the bypass graft, BOLD-CVR maps added information on the hemodynamic status and changes at the brain tissue level. Intraoperative BOLD-CVR is feasible and safe in patients undergoing EC-IC bypass revascularization. This technique can offer immediate hemodynamic feedback on brain tissue revascularization after bypass flow augmentation surgery.
\end{abstract}

https://thejns.org/doi/abs/10.3171/2018.11.FOCUS18502

KEYWORDS EC-IC bypass; BOLD; functional MRI; steno-occlusive disease; cerebrovascular

I NTRAOPERATIVE hemodynamic assessment tools greatly assist in evaluating function and patency of extracranial-intracranial (EC-IC) bypass revascularization for flow augmentation. ${ }^{1,12}$ In particular, the use of intraoperative volumetric flow measurements and video-assisted indocyanine green (ICG), including the recent development of infrared local flow analysis, ${ }^{16,17}$ have unequivocally shown their benefit. ${ }^{2,5,13}$ This hemodynamic information, however, is only provided on a vascular level and gives no insight into the hemodynamic state at the brain tissue lev$\mathrm{el}$, and it does not reveal changes in brain tissue perfusion immediately after bypass revascularization, especially in areas distant from the anastomosis. Therefore, it can only be assumed that the flow measured through the bypass graft is sufficient for the vascular territory downstream to maintain brain tissue function and integrity. Obtaining early information on brain tissue reperfusion could further expand our knowledge on bypass performance and, therefore, allow for better evaluation of its efficacy.

Such early hemodynamic feedback may be of interest when the measured flow through the bypass anastomosis is lower than expected. Furthermore, the recipient artery may only perfuse an isolated vascular territory, i.e., brain tissue volume can remain that has, in effect, not been revascularized. On the other hand, hyperperfusion syndrome may be detected, prompting an adapted perioperative management in order to prevent hemorrhage during the postoperative course.

Information about brain tissue integrity and perfusion is usually assessed during the postoperative course using

ABBREVIATIONS $A C A=$ anterior cerebral artery; $B O L D=$ blood oxygen level-dependent; $C V R=$ cerebrovascular reactivity; $E C=$ extracranial; $I C=$ intracranial; $I C A=$ internal carotid artery; ICG = indocyanine green; MCA = middle cerebral artery; mRS = modified Rankin Scale; NIHSS = National Institutes of Health Stroke Scale; STA = superficial temporal artery.

SUBMITTED September 27, 2018. ACCEPTED November 6, 2018.

INCLUDE WHEN CITING DOI: 10.3171/2018.11.FOCUS18502.

${ }^{*}$ G.M. and C.H.B.v.N. contributed equally to this work. 
TABLE 1. Characteristics of the patients included in the study

\begin{tabular}{|c|c|c|c|c|c|}
\hline & Case 1 & Case 2 & Case 3 & Case 4 & Case 5 \\
\hline Age (yrs), sex & $68, F$ & $66, F$ & $49, \mathrm{~F}$ & $62, \mathrm{~F}$ & $50, \mathrm{M}$ \\
\hline Clinical presentation & $\begin{array}{l}\text { Rt hemisyn- } \\
\text { drome }\end{array}$ & Rt arm \& leg paresis & $\begin{array}{l}\text { Motoric aphasia, rt } \\
\text { hemisyndrome }\end{array}$ & $\begin{array}{l}\text { Rt hand apraxia, } \\
\text { aphasia }\end{array}$ & $\begin{array}{l}\text { Dysarthria, It upper } \\
\text { limb numbness \& } \\
\text { lower limb paresis }\end{array}$ \\
\hline Acute/chronic symptoms & Chronic & Chronic & Chronic & Chronic & Chronic \\
\hline Diagnosis & $\begin{array}{l}\text { Lt ICA occlu- } \\
\text { sion }\end{array}$ & $\begin{array}{l}\text { Lt ICA compression w/ } \\
\text { pseudoocclusion (cav- } \\
\text { ernous sinus tumor) }\end{array}$ & $\begin{array}{l}\text { Moyamoya syndrome w/ } \\
\text { atypical It hemispheric } \\
\text { bleeding }\end{array}$ & $\begin{array}{l}\text { Rt intracranial } \\
\text { ICA, MCA, \& } \\
\text { ACA occlusion }\end{array}$ & Rt ICA occlusion \\
\hline Hemodynamic failure stage & II & 1 & 1 & II & II \\
\hline Smoking & No & No & No & Yes & No \\
\hline Hypertension & Yes & Yes & No & No & Yes \\
\hline Hypercholesterolemia & Yes & Yes & No & No & Yes \\
\hline Obesity & Yes & No & No & No & No \\
\hline Diabetes & Yes & No & No & No & No \\
\hline Previous bleedings & No & No & No & No & No \\
\hline Family history & No & No & No & Yes & No \\
\hline NIHSS score at presentation & 2 & 1 & 9 & 1 & 4 \\
\hline mRS score at presentation & 1 & 0 & 3 & 1 & 2 \\
\hline Involved territory & Lt MCA+ACA & Lt MCA & Lt MCA & Rt MCA & Rt MCA+ACA \\
\hline Preanastomotic flow (recipient vessel) & $1 \mathrm{ml} / \mathrm{min}$ & $1 \mathrm{ml} / \mathrm{min}$ & $3 \mathrm{ml} / \mathrm{min}$ & NA & $<1 \mathrm{ml} / \mathrm{min}$ \\
\hline Postanastomotic flow (recipient vessel) & $14 \mathrm{ml} / \mathrm{min}$ & $10 \mathrm{ml} / \mathrm{min}$ & $15 \mathrm{ml} / \mathrm{min}$ & $\begin{array}{l}\text { (Double barrel) } \\
40+48 \mathrm{ml} / \mathrm{min}\end{array}$ & $16 \mathrm{ml} / \mathrm{min}$ \\
\hline Recipient vessel & $\mathrm{M}_{4}$ & $\mathrm{M}_{4}$ & $\mathrm{M}_{4}$ & $\mathrm{M}_{3}+\mathrm{M}_{4}$ & $\mathrm{M}_{3}$ \\
\hline Bypass patency (ICG) & Yes & Yes & Yes & Yes & Yes \\
\hline Bypass patency (intraop MRA) & Yes & Yes & Yes & Yes & Yes \\
\hline Postop complications & No & No & No & $\begin{array}{l}\text { Hyperperfusion } \\
\text { syndrome }\end{array}$ & No \\
\hline Bypass patency (postop CTA) & Yes & NA & Yes & Yes & Yes \\
\hline
\end{tabular}

$\mathrm{NA}=$ not available.

PET, ${ }^{19}$ perfusion MRI, ${ }^{4,14}$ perfusion $\mathrm{CT},{ }^{23}$ or cerebrovascular reactivity (CVR). ${ }^{11,15}$ The application of intraoperative high-field MRI may deliver such information directly after the bypass anastomosis. By obtaining functional MRI blood oxygenation level-dependent (BOLD) volumes during repeated cycles of apnea, CVR can be measured at the brain tissue level. We previously reported the feasibility of intraoperative 3-T MRI BOLD-CVR and its preliminary application for neurovascular surgery. ${ }^{6}$

The purpose of this study was to assess whether intraoperative BOLD-CVR can offer hemodynamic information at the brain tissue level directly after revascularization and whether this imaging technique is feasible and safe in patients undergoing an EC-IC bypass revascularization for flow augmentation.

\section{Methods}

The study was approved by the ethics board of our institution. All patients electively selected for a superficial temporal artery-middle cerebral artery (STA-MCA) bypass flow augmentation surgery from January 2015 until July 2016 were invited to participate in this study and gave informed consent. Exclusion criteria were the general MRI contraindications and/or refusal to participate in the study. No patient had to be excluded. Table 1 summarizes the patients' characteristics. All patients had also undergone preoperative $\mathrm{H}_{2}\left({ }^{15} \mathrm{O}\right)$-PET scanning to assess hemodynamic failure, according to standard clinical protocol.

\section{Intraoperative CVR Data Acquisition and Analysis}

After successful STA-MCA microanastomosis, each patient underwent intraoperative scanning on a 3-T MRI scanner according to an established protocol and BOLDCVR analysis as previously published by our group. ${ }^{6} \mathrm{Be}-$ fore the MRI transfer, a checklist was used to minimize any risk to the patient. ${ }^{22} \mathrm{~A}$ sedated and intubated patient was transferred to the intraoperative MR suite (3T Skyra VD13 MRI, Siemens). ${ }^{22}$ Whole-brain BOLD volumes were collected with an axial 7.20 min 2D EPI (echo planar imaging) BOLD sequence with voxel size $3 \times 3 \times 3 \mathrm{~mm}^{3}$, acquisition of matrix $64 \times 64,35$ slices with ascending interleaved acquisition, slice gap $0.3 \mathrm{~mm}$, GRAPPA (generalized autocalibrating partially parallel acquisitions) factor 2 with 32 reference lines, adaptive coil combination, auto coil selection, TR $2000 \mathrm{msec}$, TE $30 \mathrm{msec}$, flip 


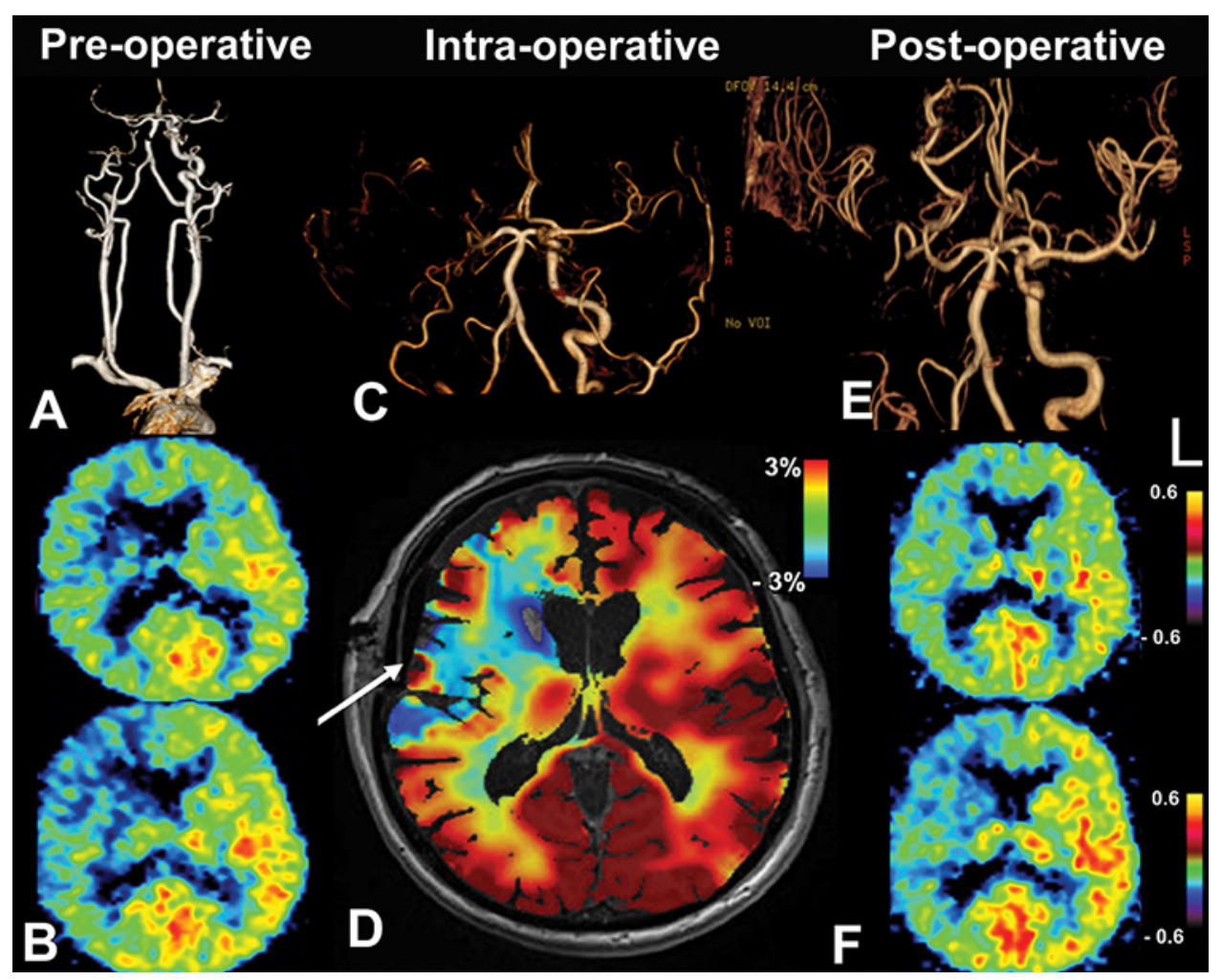

FIG. 1. Case 5. Right-sided EC-IC bypass flow augmentation surgery. A: Preoperative MR angiogram showing a right ICA occlusion. B: Preoperative $\mathrm{H}_{2} \mathrm{O}$-PET scans (baseline scan, upper; after Diamox administration, lower) with reduced perfusion reserve in the right ACA and MCA territories. The color scale refers to $\mathrm{ml} / \mathrm{ml}$ tissue/min. C: Intraoperative MR angiogram showing good bypass patency. D: Intraoperative BOLD MR image showing positive CVR values in the revascularized hemisphere (white arrow indicates the bypass zone with good hemodynamic status around it) with persisting areas with steal phenomenon, depicted in blue (CVR values are calculated as \% $\triangle B O L D$ signal). E: Postoperative MR angiogram obtained at 3 months with good depiction of the terminal MCA trunks, hinting at a sufficient bypass patency. F: Three-month postoperative PET scan showing a persisting stage II hemodynamic failure (color scale refers to $\mathrm{ml} / \mathrm{ml}$ tissue $/ \mathrm{min}$ ). $\mathrm{L}=$ left.

angle $85^{\circ}$, bandwidth $2368 \mathrm{~Hz} / \mathrm{Px}, 220$ volumes, and field of view $192 \times 192 \mathrm{~mm}$. For coregistration of the functional sequence, skull stripping, and overlay purposes, an anatomical T1-weighted MPRAGE (magnetization prepared rapid acquisition) sequence (voxel size $0.5 \times 0.5 \times 0.9 \mathrm{~mm}$; field of view read $240 \mathrm{~mm}$; slice thickness $0.90 \mathrm{~mm}$; TR $1900.0 \mathrm{msec}$; TE $2.60 \mathrm{msec}$; filter: prescan normalize, flip angle $9^{\circ}$; base resolution 256; phase resolution $100 \%$; interpolation to $512 \times 512$; and PAT [parallel acquisition techniques] mode GRAPPA) from the clinical protocol was used. The field of view from the BOLD image acquisition was copied to the T1-weighted image for better early realignment of both images. After obtaining the BOLD and non-contrast-enhanced T1-weighted sequences, additional diffusion weighted imaging, T2-weighted sequences, and time-of-flight MRA were obtained. Carbon dioxide changes (hypercapnia) were induced by three 44 -second separated blocks of apnea with an interval period of 88 seconds of ventilated breathing. ${ }^{6}$ CVR calculations were done based on the frequency-adjusted sine model as described previously. ${ }^{24}$

CVR values, calculated as the average BOLD signal change between apnea and baseline (\% $\%$ BOLD signal), were color-coded (from blue: $-3 \%$ to red: $+3 \%$ ) and overlaid on T1 anatomical scans (Figs. 1-3).

\section{Results}

\section{Patient Characteristics}

Five patients ( 4 women) were included, with a mean age of $58.6 \pm 9.1$ years (Table 1). The mean anesthesia time was $487 \pm 75.7$ minutes including surgery and intraoperative MRI. The mean duration of the surgical procedures was $237 \pm 92.8$ minutes, with the mean dedicated MRI duration (scanning plus transfer time) being $63 \pm 23.9$ minutes.

Intraoperatively, no new diffusion restrictions were seen on MRI, and postoperatively none of the patients exhibited new neurological symptoms. On day 3,1 patient (case 4) presented with a 2-fold episode of generalized seizures without evidence of new ischemia or hemorrhages. None of the patients exhibited novel persistent neurological symptoms during the immediate postoperative course.

Table 2 shows intraoperative CVR values for all patients. On average, patients presented with marked lower CVR on the affected hemisphere (affected hemisphere vs unaffected hemisphere: $0.67 \pm 0.68$ vs $1.1 \pm 0.69, p=0.04$ $\mathrm{t}$-test). During the qualitative assessment, a strong cortical CVR response was seen for each patient at the anatomical location of the bypass (Figs. 1-3). 


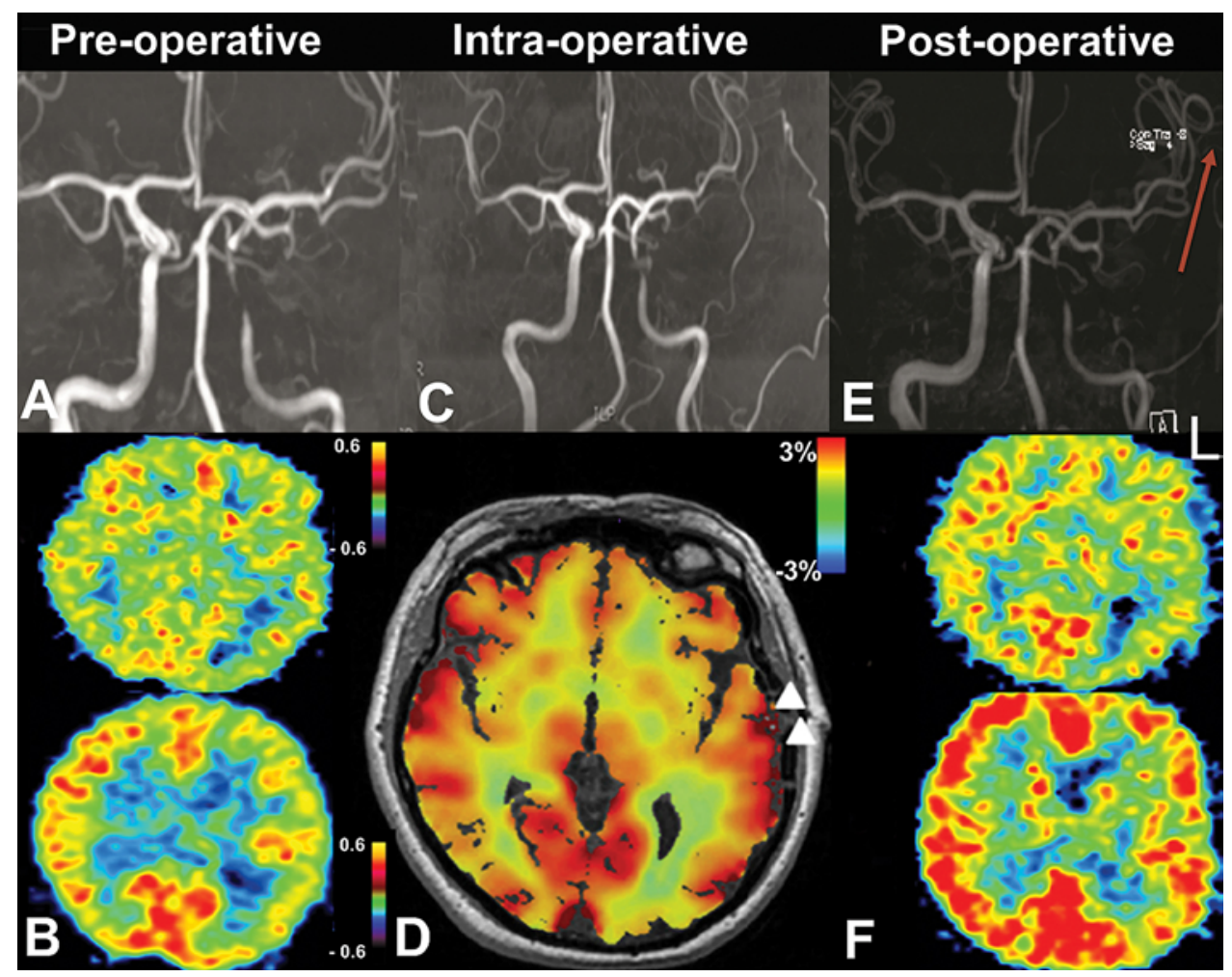

FIG. 2. Case 2. Left-sided EC-IC bypass flow augmentation surgery. A: Preoperative MR angiogram with evidence of a left cavernous carotid compression. B: Preoperative $\mathrm{H}_{2} \mathrm{O}-\mathrm{PET}$ scans showing reduced baseline perfusion (upper) and reduced perfusion reserve in the affected left hemisphere (lower). The color scale refers to $\mathrm{ml} / \mathrm{ml}$ tissue/min. C: Intraoperative MR angiogram with good depiction of the bypass. D: Intraoperative BOLD MRI showing positive CVR values in the revascularized area (color scale refers to CVR values, calculated as \% $\triangle B O L D$ signal, arrowheads indicate the site of the STA-MCA anastomosis). E: Postoperative follow-up MR angiogram showing a very weak flow through the bypass (red arrow). The site of the anastomosis could not be clearly identified, and the bypass was considered occluded. F: Postoperative $\mathrm{H}_{2} \mathrm{O}-\mathrm{PET}$ scans showing a better baseline perfusion (upper) and good perfusion reserve (lower). The color scale refers to $\mathrm{ml} / \mathrm{ml}$ tissue/min.

\section{Illustrative Cases Case 5}

A 50-year-old man presented to our institution after 2 episodes of dysarthria, left-hand dysesthesia, and mild paresis of the left leg (National Institutes of Health Stroke Scale [NIHSS] score 4; modified Rankin Scale [mRS] score: 2). Vascular risk factors were hypercholesterolemia and hypertension. The patient underwent MRI/MRA assessment and was diagnosed with an occlusion of the right internal carotid artery (ICA; Fig. 1A). Consecutive evaluation of the cerebral hemodynamic status with $\mathrm{H}_{2}\left({ }^{15} \mathrm{O}\right)$-PET scanning, in combination with an acetazolamide challenge, showed stage II hemodynamic failure in the right anterior cerebral artery (ACA) and MCA territories (Fig. 1B). ${ }^{3}$ Despite optimal medical treatment, the patient exhibited a worsening of symptoms and was selected for a right-sided STA-MCA bypass procedure. A temporal $\mathrm{M}_{3}$ branch was chosen as a recipient vessel.

The preanastomosis flow in the recipient vessel, measured with a microflow probe, was less than $1 \mathrm{ml} / \mathrm{min}$ (HT 313 Transonic flow-QC meter, Transonic System Inc.). The flow in the recipient vessel increased to $16 \mathrm{ml} / \mathrm{min}$ after the bypass anastomosis, which, in concordance with the video-assisted ICG findings, was interpreted as a patent bypass. Intraoperative MRA confirmed a patent bypass, and concomitant BOLD-CVR clearly showed a CVR change in the cortical areas surrounding the STA-MCA bypass anastomosis, which was only a local improvement in comparison with the preoperative PET study (Fig. 1C and $\mathrm{D})$. In the following months, the patient experienced recurrent symptoms. At 3 months, the $\mathrm{H}_{2}\left({ }^{15} \mathrm{O}\right)$-PET scan showed persistence of stage II hemodynamic failure (Fig. $1 \mathrm{~F})$. The microanastomosis, as well as the distal $\mathrm{M}_{4}$ segment vessels of the MCA, remained visible on MRA, consistent with a patent bypass (Fig. 1E). The patient's symptoms slowly improved after 8 months postsurgery.

\section{Case 2}

This 66-year-old woman presented to our clinic with a recurrent transient right brachiocrural paresis (NIHSS score $1 ; \mathrm{mRS}$ score 0 on admission). Neuroimaging revealed a high-grade stenosis of the left intracavernous segment of the ICA secondary to compression of a progressive invasive left cavernous sinus meningioma (Fig. 2A). $\mathrm{H}_{2}\left({ }^{15} \mathrm{O}\right)$-PET imaging demonstrated stage I hemodynamic failure in the left MCA territory as shown in Fig. 2B. Since the patient presented with progressive neurological symptoms despite optimal medical treatment, she was se- 


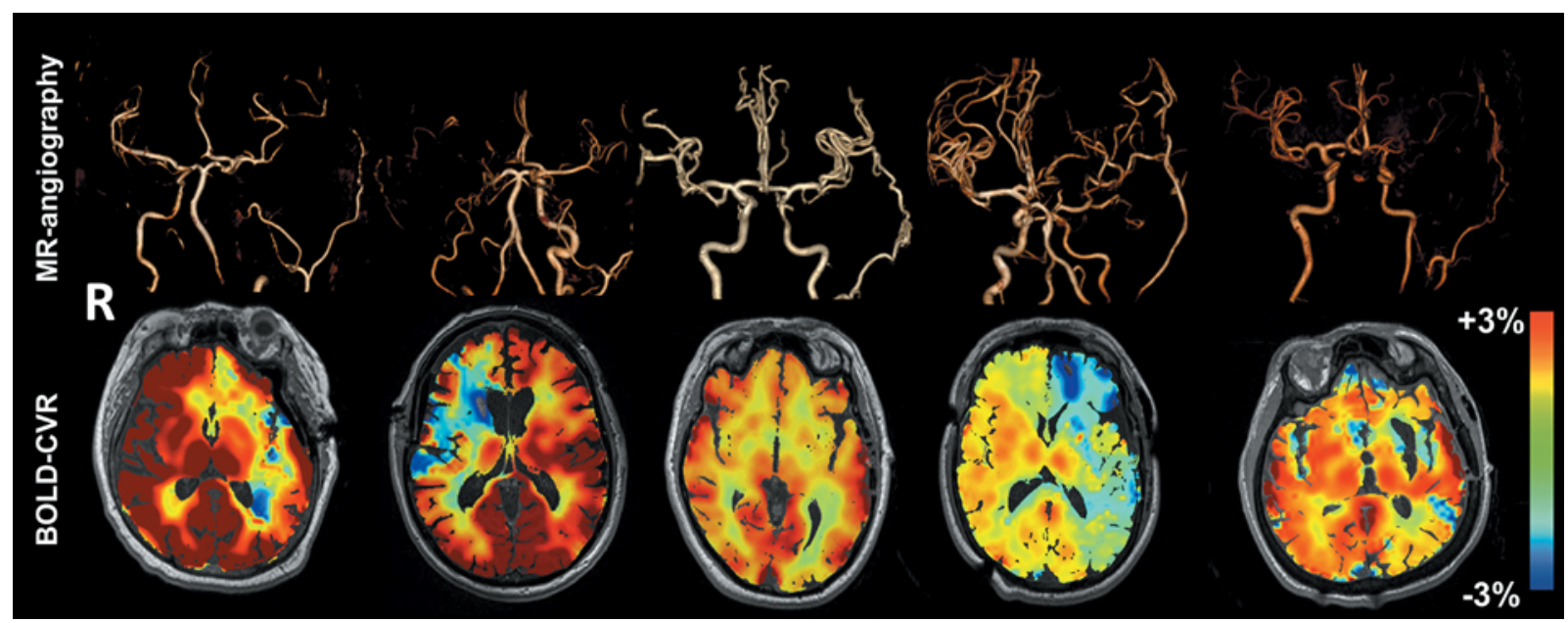

FIG. 3. Synopsis of intraoperative MRA and BOLD-CVR maps at the level of the STA-MCA anastomosis for the 5 patients. As in Fig. 1, CVR maps are color-coded ranging from normal values (red) to impaired values (blue). CVR values are calculated as variation of $B O L D$ signal ( $\% \triangle B O L D$ signal). Blue areas represent brain regions with impaired hemodynamic status.

lected to undergo a left STA-MCA bypass flow augmentation procedure. Intraoperative preanastomosis flow on the recipient vessel showed a flow of $1 \mathrm{ml} / \mathrm{min}$, whereas the postanastomosis values reached $10 \mathrm{ml} / \mathrm{min}$. Videoassisted ICG confirmed the bypass patency, although with weak flow, which was also confirmed on intraoperative MRA (Fig. 2C). Intraoperative CVR improved in the entire revascularized hemisphere (Fig. 2D). The follow-up $\mathrm{H}_{2}\left({ }^{15} \mathrm{O}\right.$ )-PET image (Fig. $2 \mathrm{~F}$ ) showed a clear improvement in the range of normal perfusion reserve values, but with an occluded bypass on MRA (Fig. 2E). In the postoperative course, the patient did not develop any new transient neurological symptoms.

\section{Discussion}

In this study, we show the feasibility and safety of intraoperative BOLD-CVR measurements in patients undergoing bypass flow augmentation surgery. The prolonged anesthesia time due to the addition of intraoperative MRI did not result in increased morbidity peri- or postoperatively. However, a longer anesthesia time could represent a matter of concern, due to the possible higher complication rate in such fragile patients.
The potential additional benefit of BOLD-CVR is the possibility of obtaining early hemodynamic information at the brain tissue level, rather than simply registering the flow inside the vessels of interest. Such early hemodynamic feedback may be of interest when the measured flow through the bypass anastomosis is lower than expected. Furthermore, the recipient artery may only perfuse an isolated vascular territory, i.e., brain tissue volume can remain that has, in effect, not been revascularized. On the other hand, hyperperfusion syndrome may be detected, prompting an adapted perioperative management in order to prevent hemorrhage during the postoperative course. As our illustrative cases show, the data obtained with intraoperative BOLD-CVR can add information to those obtained with conventional methods, such as ICG or MRA.

As previously demonstrated,,${ }^{9,15,20}$ low CVR is associated with a higher stroke risk. Patients with persistent symptoms and low BOLD-CVR values postoperatively (as in case 1) are still at risk of major stroke events until their BOLD-CVR and symptoms improve. Therefore, even if intraoperative BOLD-CVR assessment could prove to be nonsuperior to other techniques for predicting the ultimate bypass efficacy in the long term, it nevertheless offers

TABLE 2. Mean intraoperative CVR values for each patient

\begin{tabular}{|c|c|c|c|c|c|c|c|c|c|}
\hline \multirow[b]{2}{*}{$\begin{array}{l}\text { Case } \\
\text { No. }\end{array}$} & \multicolumn{3}{|c|}{ Intraop } & \multicolumn{2}{|c|}{ Preop } & \multicolumn{2}{|c|}{ Intraop } & \multicolumn{2}{|c|}{ Unaffected vs Affected Hemisphere } \\
\hline & $\begin{array}{l}\text { Whole } \\
\text { Brain }\end{array}$ & $\begin{array}{l}\text { Gray } \\
\text { Matter }\end{array}$ & $\begin{array}{l}\text { White } \\
\text { Matter }\end{array}$ & $\begin{array}{c}\text { Affected } \\
\text { Hemisphere }\end{array}$ & $\begin{array}{l}\text { Unaffected } \\
\text { Hemisphere }\end{array}$ & $\begin{array}{c}\text { Affected } \\
\text { Hemisphere }\end{array}$ & $\begin{array}{l}\text { Unaffected } \\
\text { Hemisphere }\end{array}$ & Preop & Intraop \\
\hline 1 & 1.4 & 1.72 & 1.01 & 0.07 & 0.13 & 1.00 & 1.95 & $84.8 \%$ & $95.5 \%$ \\
\hline 2 & 2.08 & 2.35 & 1.62 & 0.02 & 0.11 & 1.54 & 2.61 & $367.1 \%$ & $69.5 \%$ \\
\hline 3 & 1.44 & 1.67 & 1.04 & 0.17 & 0.21 & 1.64 & 1.22 & $24.9 \%$ & $-25.6 \%$ \\
\hline 4 & 0.16 & 0.18 & 0.16 & 0.13 & 0.26 & 0.03 & 0.28 & $102.2 \%$ & $817.5 \%$ \\
\hline 5 & 0.76 & 0.84 & 0.58 & 0.27 & 0.32 & 0.71 & 0.81 & $19 \%$ & $15 \%$ \\
\hline
\end{tabular}

CVR is calculated as percentage change of BOLD signal during the breath-hold challenge.

* The ratios between CVR values in the unaffected and affected hemispheres were calculated as percentages using the following formula: $\left(C V R_{\text {unaffected hemisphere }}-\right.$ CVR $_{\text {af- }}$ fected hemisphere $) \times 100 /$ CVR $_{\text {affected hemisphere }}$. 
unique insight into the hemodynamics associated with revascularization and allows for prediction of postoperative clinical evolution and stroke risk. However, these assumptions need to be confirmed by future studies with larger cohorts and longer follow-up.

\section{BOLD-CVR in Chronic Steno-Occlusive Diseases}

Cerebrovascular reactivity is a functional imaging marker describing the degree of vasodilation of a vessel in response to a vasoactive stimulus and is often measured using BOLD MRI ${ }^{11}$ in combination with $\mathrm{CO}_{2}$ as a vasoactive agent. ${ }^{8} \mathrm{CO}_{2}$-induced BOLD-CVR imaging is known to be useful in predicting stroke risk, especially in the presence of areas with negative CVR (i.e., steal phenomena or stage II hemodynamic failure), where postoperative CVR imaging is predictive of clinical outcome, as well as brain tissue changes following revascularization surgery. ${ }^{7,9,15,21}$

Still, little is known about the potential of intraoperative CVR imaging and we only recently reported the feasibility of obtaining valuable BOLD MRI sequences to study CVR. ${ }^{6}$ A relevant change in intraoperative CVR after revascularization surgery might be a first sign of a proper blood supply to previous ischemic territories and, on the contrary, a low CVR in territories expected to show a rise in CVR values, could suggest the inefficacy of the bypass.

\section{Alternative Novel Intraoperative Blood Flow Imaging Techniques}

A previous intraoperative study using MRI in patients undergoing EC-IC bypass was conducted by Wang et al. ${ }^{25}$ They concluded that this knowledge can help anticipate a hyperperfusion syndrome. Intraoperative data of cerebral blood flow changes after revascularization surgery were obtained with perfusion CT by Xue et al. ${ }^{26}$ in patients undergoing carotid endarterectomy. In comparison with perfusion CT scanning, MRI has the advantage of no ionizing radiation and less contrast-induced adverse reactions, as well as a higher spatial resolution, allowing for better detection of early and more-subtle hemodynamic changes. ${ }^{18}$ In addition to all of these advantages, contrast agents are not needed for BOLD-CVR.

\section{Limitations}

We have to stress that these BOLD-CVR images were not used for clinical decision-making. Such hemodynamic maps need to be carefully interpreted, and their potential prognostic value in actually predicting the success of EC-IC revascularization surgery obviously needs to be confirmed. The ultimate goal would be to have intraoperative quantitative CVR values as a predictor of bypass efficacy and functional outcome. We aim to answer this in the future with a larger patient cohort and longer followup. Even though we found no complications related to the intraoperative BOLD-CVR assessment, we are limited by the small number of our cohort.

Furthermore, the breath-holding technique is a practical method of delivering $\mathrm{CO}_{2}$ to a patient, but its quantification and therefore the reproducibility of the vasoactive stimulus remain challenging. CVR values were not live, but were obtained in postprocessing after the scan. In order to obtain information, MR data must be processed separately, as previously described. ${ }^{24}$ This could take up to 30 minutes. Nevertheless, as described by our illustrative cases, this information could be relevant for further surgical decisions on whether to perform bypass revision or not. Further development of this technique and automation of data analysis can help in providing important information for surgical decision-making.

The information obtained at the brain tissue level could suggest the need to revise the anastomosis, but this may not be feasible in some circumstances due to difficulty in finding other recipient vessels or technical nuisances in performing a new anastomosis. However, other techniques like ICG, flow measurements, and eventually angiography or MRA are used frequently to assess the bypass. Even though revising an anastomosis might be hard or unfeasible in some cases, we think intraoperative assessment is and will be a valuable tool in revascularization surgery. This technique is not appropriate for indirect revascularization techniques like encephalomyosynangiosis, encephaloduroarteriosynangiosis, or encephaloduromyoarteriosynangiosis, because they are based on neoangiogenesis occurring weeks to months after the procedure. ${ }^{10}$ Measuring intraoperative BOLD-CVR in patients undergoing these types of revascularization would not show any immediate change to the hemodynamic status in comparison to the preoperative situation.

\section{Conclusions}

Intraoperative BOLD-CVR assessment in patients undergoing EC-IC bypass revascularization is feasible and safe. Its efficacy in providing immediate hemodynamic information following bypass flow augmentation surgery will need to be studied in further detail.

\section{Acknowledgments}

This work was supported by a personal research grant to Dr. Jorn Fierstra of the University Zurich (Forschungskredit; Postdoc. FK-16-040).

\section{References}

1. Amin-Hanjani S, Shin JH, Zhao M, Du X, Charbel FT: Evaluation of extracranial-intracranial bypass using quantitative magnetic resonance angiography. J Neurosurg 106:291-298, 2007

2. Charbel FT, Gonzales-Portillo G, Hoffman WE, Ostergren LA, Misra M: Quantitative assessment of vessel flow integrity for aneurysm surgery. Technical note. J Neurosurg 91:1050-1054, 1999

3. Esposito G, Amin-Hanjani S, Regli L: Role of and indications for bypass surgery after Carotid Occlusion Surgery Study (COSS)? Stroke 47:282-290, 2016

4. Esposito G, Della Pepa GM, Sabatino G, Gaudino S, Puca A, Maira G, et al: Bilateral flow changes after extracranialintracranial bypass surgery in a complex setting of multiple brain-feeding arteries occlusion: the role of perfusion studies. Br J Neurosurg 29:723-725, 2015

5. Esposito G, Regli L: Intraoperative tools for cerebral bypass surgery. Acta Neurochir (Wien) 160:775-778, 2018

6. Fierstra J, Burkhardt JK, van Niftrik CH, Piccirelli M, Pangalu A, Kocian R, et al: Blood oxygen-level dependent functional assessment of cerebrovascular reactivity: feasibility for 
intraoperative 3 Tesla MRI. Magn Reson Med 77:806-813, 2017

7. Fierstra J, Poublanc J, Han JS, Silver F, Tymianski M, Crawley AP, et al: Steal physiology is spatially associated with cortical thinning. J Neurol Neurosurg Psychiatry 81:290293, 2010

8. Fierstra J, Sobczyk O, Battisti-Charbonney A, Mandell DM, Poublanc J, Crawley AP, et al: Measuring cerebrovascular reactivity: what stimulus to use? J Physiol 591:5809-5821, 2013

9. Fierstra J, van Niftrik C, Warnock G, Wegener S, Piccirelli M, Pangalu A, et al: Staging hemodynamic failure with blood oxygen-level-dependent functional magnetic resonance imaging cerebrovascular reactivity: a comparison versus gold standard $\left({ }^{15} \mathrm{O}-\right) \mathrm{H}_{2} \mathrm{O}$-positron emission tomography. Stroke 49:621-629, 2018

10. Griessenauer CJ, Lebensburger JD, Chua MH, Fisher WS III, Hilliard L, Bemrich-Stolz CJ, et al: Encephaloduroarteriosynangiosis and encephalomyoarteriosynangiosis for treatment of moyamoya syndrome in pediatric patients with sickle cell disease. J Neurosurg Pediatr 16:64-73, 2015

11. Heyn C, Poublanc J, Crawley A, Mandell D, Han JS, Tymianski M, et al: Quantification of cerebrovascular reactivity by blood oxygen level-dependent MR imaging and correlation with conventional angiography in patients with Moyamoya disease. AJNR Am J Neuroradiol 31:862-867, 2010

12. Horn P, Vajkoczy P, Schmiedek P, Neff W: Evaluation of extracranial-intracranial arterial bypass function with magnetic resonance angiography. Neuroradiology 46:723-729, 2004

13. Januszewski J, Beecher JS, Chalif DJ, Dehdashti AR: Flowbased evaluation of cerebral revascularization using nearinfrared indocyanine green videoangiography. Neurosurg Focus 36(2):E14, 2014

14. Li Z, Zhou P, Xiong Z, Ma Z, Wang S, Bian H, et al: Perfusion-weighted magnetic resonance imaging used in assessing hemodynamics following superficial temporal artery-middle cerebral artery bypass in patients with Moyamoya disease. Cerebrovasc Dis 35:455-460, 2013

15. Mandell DM, Han JS, Poublanc J, Crawley AP, Fierstra J, Tymianski M, et al: Quantitative measurement of cerebrovascular reactivity by blood oxygen level-dependent MR imaging in patients with intracranial stenosis: preoperative cerebrovascular reactivity predicts the effect of extracranialintracranial bypass surgery. AJNR Am J Neuroradiol 32:721-727, 2011

16. Prinz V, Hecht N, Kato N, Vajkoczy P: FLOW 800 allows visualization of hemodynamic changes after extracranial-tointracranial bypass surgery but not assessment of quantitative perfusion or flow. Neurosurgery 10 (Suppl 2):231-239, 2014

17. Rennert RC, Strickland BA, Ravina K, Bakhsheshian J, Fredrickson V, Carey J, et al: Intraoperative assessment of cortical perfusion after intracranial-to-intracranial and extracranialto-intracranial bypass for complex cerebral aneurysms using Flow 800. Oper Neurosurg (Hagerstown) [epub ahead of print], 2018

18. Sam K, Poublanc J, Sobczyk O, Han JS, Battisti-Charbonney A, Mandell DM, et al: Assessing the effect of unilateral cerebral revascularisation on the vascular reactivity of the nonintervened hemisphere: a retrospective observational study. BMJ Open 5:e006014, 2015

19. Schick U, Zimmermann M, Stolke D: Long-term evaluation of EC-IC bypass patency. Acta Neurochir (Wien) 138:938943, 1996

20. Silvestrini M, Vernieri F, Pasqualetti P, Matteis M, Passarelli F, Troisi E, et al: Impaired cerebral vasoreactivity and risk of stroke in patients with asymptomatic carotid artery stenosis. JAMA 283:2122-2127, 2000

21. So Y, Lee HY, Kim SK, Lee JS, Wang KC, Cho BK, et al: Prediction of the clinical outcome of pediatric moyamoya disease with postoperative basal/acetazolamide stress brain perfusion SPECT after revascularization surgery. Stroke 36:1485-1489, 2005

22. Stienen MN, Fierstra J, Pangalu A, Regli L, Bozinov O: The Zurich checklist for safety in the intraoperative magnetic resonance imaging suite: technical note. Oper Neurosurg (Hagerstown) [epub ahead of print], 2018

23. Teng MM, Jen SL, Chiu FY, Kao YH, Lin CJ, Chang FC: Change in brain perfusion after extracranial-intracranial bypass surgery detected using the mean transit time of computed tomography perfusion. J Chin Med Assoc 75:649-653, 2012

24. van Niftrik CH, Piccirelli M, Bozinov O, Pangalu A, Valavanis A, Regli L, et al: Fine tuning breath-hold-based cerebrovascular reactivity analysis models. Brain Behav 6:e00426, 2016

25. Wang D, Zhu F, Fung KM, Zhu W, Luo Y, Chu WC, et al: Predicting cerebral hyperperfusion syndrome following superficial temporal artery to middle cerebral artery bypass based on intraoperative perfusion-weighted magnetic resonance imaging. Sci Rep 5:14140, 2015

26. Xue Z, Peng D, Sun Z, Wu C, Xu B, Wang F, et al: Intraoperative perfusion computed tomography in carotid endarterectomy: initial experience in 16 cases. Med Sci Monit 22:3362-3369, 2016

\section{Disclosures}

Siemens provides reference site visits for the Department of Neurosurgery, University Hospital Zurich.

\section{Author Contributions}

Conception and design: Muscas, van Niftrik, Fierstra, Sebök, Burkhardt, Valavanis, Regli, Bozinov. Acquisition of data: all authors. Analysis and interpretation of data: Muscas, van Niftrik, Piccirelli, Pangalu. Drafting the article: Muscas, van Niftrik, Bozinov. Critically revising the article: all authors. Reviewed submitted version of manuscript: all authors. Approved the final version of the manuscript on behalf of all authors: Muscas. Statistical analysis: Muscas, van Niftrik. Administrative/technical/material support: Valavanis, Regli, Bozinov. Study supervision: Valavanis, Regli, Bozinov.

\section{Supplemental Information}

\section{Previous Presentations}

Portions of this work were presented in abstract form at the 69th Congress of the German Neurosurgical Society in Münster, Germany, June 7, 2018; at the 7th Meeting of the Vascular Section of the European Association of Neurosurgical Societies in Nice, France, September 8, 2018; and in poster form at the Joint Annual Meeting of the Swiss Societies of Neurosurgery and Neuroradiology, Lugano, Switzerland, May 24-26, 2018.

\section{Correspondence}

Giovanni Muscas: Klinik für Neurochirurgie, UniveristätsSpital Zürich, Switzerland.muscas.giovanni@gmail.com. 